\title{
Prognostic value of lipoprotein (a) level in patients with coronary artery disease: a meta-analysis
}

\author{
Zhimiao Wang ${ }^{1}$, Xincheng Zhai ${ }^{2}$, Mei Xue ${ }^{1}$, Wenjuan Cheng $^{1}$ and Hesheng $\mathrm{Hu}^{1 *}$ (D)
}

\begin{abstract}
Background: Elevated lipoprotein (a) is recognized as a risk factor for incident cardiovascular events in the general population and established cardiovascular disease patients. However, there are conflicting findings on the prognostic utility of elevated lipoprotein (a) level in patients with coronary artery disease (CAD).Thus, we performed a metaanalysis to evaluate the prognostic value of elevated lipoprotein (a) level in CAD patients.

Methods and results: A systematic literature search of PubMed and Embase databases was conducted until April 16, 2019. Observational studies reporting the prognostic value of elevated lipoprotein (a) level for cardiac events (cardiac death and acute coronary syndrome), cardiovascular events (death, stroke, acute coronary syndrome or coronary revascularisation), cardiovascular death, and all-cause mortality in CAD patients were included. Pooled multivariable adjusted risk ratio (RR) and 95\% confidence interval (Cl) for the highest vs. the lowest lipoprotein (a) level were utilized to calculate the prognostic value. Seventeen studies enrolling 283,328 patients were identified. Meta-analysis indicated that elevated lipoprotein (a) level was independently associated with an increased risk of cardiac events (RR 1.78; 95\% Cl 1.31-2.42) and cardiovascular events (RR 1.29; 95\% Cl 1.17-1.42) in CAD patients. However, elevated lipoprotein (a) level was not significantly associated with an increased risk of cardiovascular mortality (RR 1.43; 95\% Cl 0.94-2.18) and all-cause mortality (RR 1.35; 95\% Cl 0.93-1.95).
\end{abstract}

Conclusions: Elevated lipoprotein (a) level is an independent predictor of cardiac and cardiovascular events in CAD patients. Measurement of lipoprotein (a) level has potential to improve the risk stratification among patients with CAD.

Keywords: Coronary artery disease, Prognosis, Mortality, Meta-analysis

\section{Backgrounds}

Coronary artery disease $(\mathrm{CAD})$ is a common type of cardiovascular disease. Despite advances in medical sciences, CAD remains the main cause of death in the world [1]. Patients with CAD are facing high risk of secondary cardiovascular events and mortality. Nevertheless, current traditional risk factors and prognostic risk models are insufficient to predict the prognosis of CAD. Thus, identification of residual predictive biomarkers is crucial for more aggressive secondary prevention of CAD patients [2].

\footnotetext{
* Correspondence: huheshengjn@tom.com

1Department of Cardiology, Shandong Provincial Qianfoshan Hospital, the First Hospital Affiliated with Shandong First Medical University, NO. 16766, Jingshi Road, Jinan city, Jinan 250014, Shandong Province, China Full list of author information is available at the end of the article
}

Lipoprotein (a) is a large low-density lipoprotein like particle involved in lipid metabolism, coagulation and fibrinolytic systems [3]. Approximately 20 to $30 \%$ of the global population have lipoprotein (a) level over $30 \mathrm{mg} /$ $\mathrm{ml}$ a), particularly in patients with established cardiovascular disease [4]. Elevated lipoprotein (a) level or hyperlipoproteinemia (a) has been identified as a risk factor for incident cardiovascular events in the general population and established cardiovascular disease patients [5]. Blood lipoprotein (a) level was strongly associated with the presence and severity of CAD [6]. Accumulating epidemiological studies [7-18] suggest that elevated blood lipoprotein (a) level could serve as an independent prognostic biomarker in patients with CAD. However, there are conflicting results [19-23] on the prognostic role of elevated blood lipoprotein (a) level in CAD patients.

(c) The Author(s). 2019 Open Access This article is distributed under the terms of the Creative Commons Attribution 4.0 International License (http://creativecommons.org/licenses/by/4.0/), which permits unrestricted use, distribution, and 
No previous systematic review or meta-analysis has focused on the prognostic value of elevated lipoprotein (a) level for mortality in patients with CAD. Therefore, this meta-analysis sought to investigate the prognostic value of baseline blood lipoprotein (a) level for cardiovascular and all-cause mortality and adverse cardiovascular events in CAD patients.

\section{Methods}

\section{Literature search}

This meta-analysis follows the guideline of Preferred Reporting Items for Systematic Reviews and Metaanalyses [24]. A systematic literature search of Pubmed and Embase databases was conducted by two independent authors until April 16, 2019. The search keywords included: "lipoprotein(a)" AND "coronary heart disease" OR "coronary artery disease" OR "myocardial infarction" OR "acute coronary syndromes" OR "unstable angina" AND "mortality" OR "death" OR "events" OR "event" AND "follow-up". In addition, reference lists of included studies and pertinent articles were also manually scanned for any possible studies.

\section{Study selection}

Studies were considered for inclusion if they satisfied the following criteria: 1) observational studies enrolling CAD patients; 2) baseline blood lipoprotein (a) level as exposure; 3) reported at least one of the following outcome measure: cardiac events (cardiac death and acute coronary syndrome[ACS]), cardiovascular events (death, stroke, ACS or coronary revascularisation), cardiovascular death, and allcause mortality; and 4) provided multivariable adjusted risk ratio (RR) or hazard ratio (HR) or odds ratio (OR) with corresponding 95\% confidence interval $(\mathrm{CI})$ of each outcome measure for the highest versus the lowest blood lipoprotein(a). Exclusion criteria were: 1) participants were not restricted in CAD patients; 2) provided risk estimate according to per unit or per SD increase lipoprotein(a) level; 3) reported unadjusted risk estimate; and 4) meeting abstracts or reviews.

\section{Data extraction and quality assessment}

Two authors independently extracted and collected the following data: last name of the first author, publication year, country, study design, type of CAD, sample size, percentage of men, mean age or age range, cutoff value of lipoprotein(a), length of follow-up, number of adverse events, fully adjusted risk estimate reported, and adjustment of variables. We assessed the methodological quality of individual studies based on the Newcastle-Ottawa Scale (NOS) for cohort studies [25]. Studies with 7 points or more were recognized as high quality. Disagreements between the authors in data extraction and quality evaluation were resolved by consensus.

\section{Statistical analysis}

All data were analyzed using STATA 12.0 version software (STATA Corp LP, College Station, TX, USA).The reported multivariable adjusted risk estimate was used to calculate the prognostic value of blood lipoprotein(a) for the highest versus the lowest level. Heterogeneity between studies was checked using the $\mathrm{I}^{2}$ statistic $\left(\mathrm{I}^{2} \geq 50 \%\right.$ indicating significant heterogeneity) and the Cochrane Q statistic $(p<0.10$ indicating significant heterogeneity). A fixed-effect model was chosen in the absence of significant heterogeneity. Otherwise, a random effect model was used. Funnel plot was scheduled to detect publication bias when more than 10 studies were analyzed. Moreover, we conducted a subgroup analysis by study design, sample sizes, follow-up duration, and whether adjusting statins use or lipids. Sensitivity analysis was performed by removal of one study at each turn to investigate the robustness of the pooling results.

\section{Results}

\section{Search results and study characteristics}

The study selection process is shown in Fig. 1. Our initial computerized literature search produced 2596 relevant records and one article was identified by a hand search. After reviewing titles and abstracts, 56 potentially relevant articles were retrieved for full-text evaluation. After applying our inclusion criteria, 39 articles were excluded for the following reasons: exposure were not lipoprotein (a); outcome measures was not interest; patients not restricted in CAD; meeting abstracts or reviews. Finally, 17 studies [7-23] were included in this meta-analysis.

Table 1 summarizes the main characteristics of these eligible studies. Ten studies [7, 8, 10, 12, 14-16, 19-21] adopted the retrospective designs and others were prospective. The included studies were published between 1998 and 2019. The sample size ranged from 115 to 7863, with a total of 283,328 patients. The length of follow-up ranged from 1.0 to 9.9 years. The cutoff value of lipoprotein varied across the included studies. Mortality events were evaluated by medical record or death certificate. Overall, there were 483 cardiac events, 3733 cardiovascular events, 1269 all-cause and 868 cardiovascular death in the included studies. Fifteen studies were awarded at least 7 points (Additional file 1 Table S1), indicating a relatively high quality.

\section{Impact of elevated lipoprotein (a) on cardiac and cardiovascular events}

Five studies $[8,10,13,16,17]$ reported the prognostic value of elevated lipoprotein (a) level for cardiac events (Fig. 2). The pooled RR of cardiac events was 1.78 (95\% CI 1.312.42) for the highest vs. the lowest category of lipoprotein (a) level in a random effect model, with significant heterogeneity $\left(\mathrm{I}^{2}=61.9 \% ; p=0.033\right)$. Sensitivity analyses revealed no significant changes in the original pooled risk estimates when any study was excluded (data not shown). 


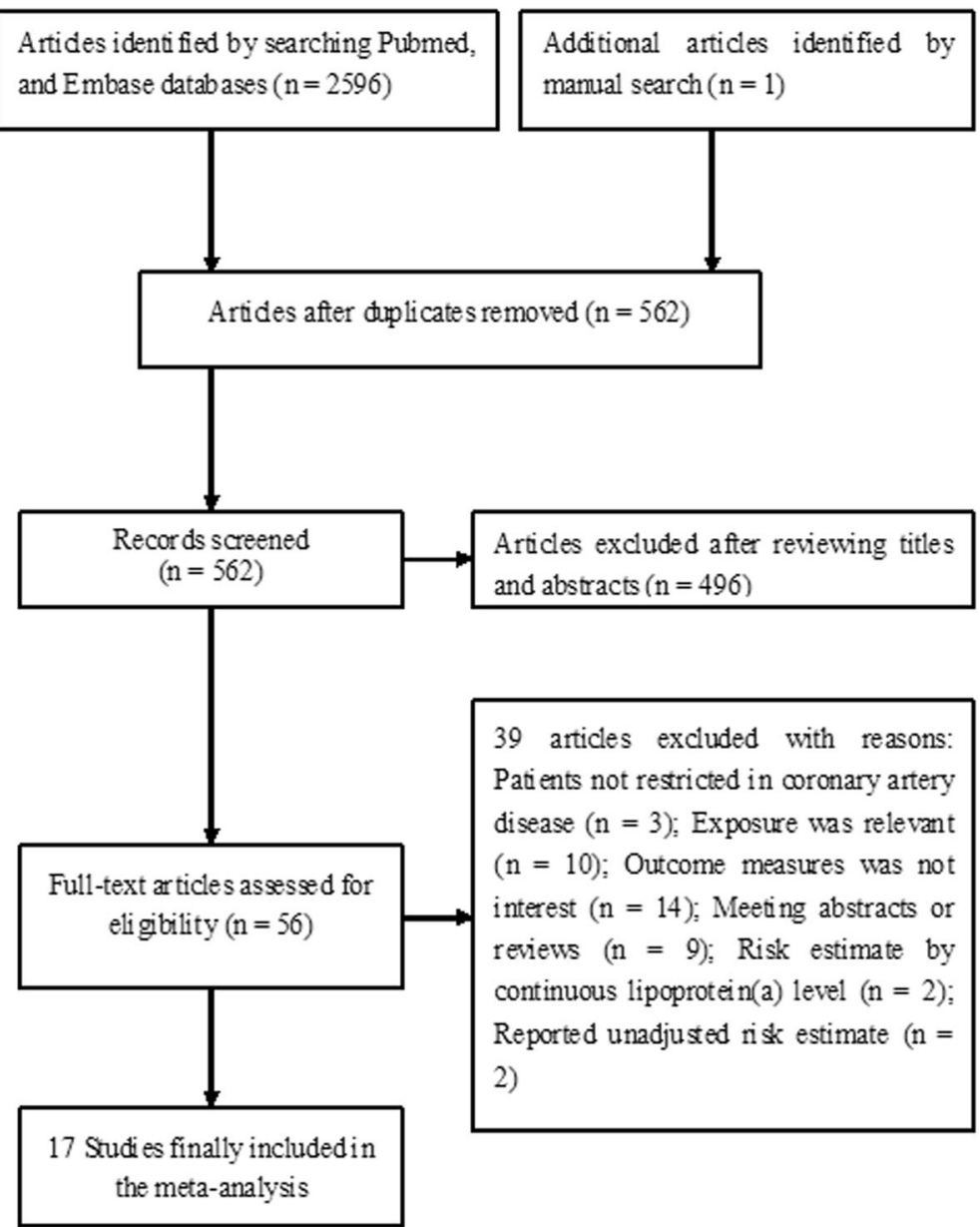

Fig. 1 Flow chart showing study selection process

Eight studies [11, 12, 14, 18, 19, 21, 23] reported the prognostic value of elevated lipoprotein (a) level for cardiovascular events (Fig. 3). The pooled RR of cardiovascular events was 1.29 (95\% CI 1.17-1.42) for the highest vs. the lowest category of lipoprotein(a) level in a fixed-effect model, without significant heterogeneity $\left(\mathrm{I}^{2}=36.2 \% ; p=\right.$ 0.140 ). Sensitivity analyses showed no significant changes in the original pooled effect sizes when any study was removed (data not shown). Subgroup analysis showed that the prognostic significance of lipoprotein (a) level for cardiovascular events was consistently found in each predefined subgroups (Additional file 2 Table S2).

\section{Impact of elevated lipoprotein (a) on all-cause and cardiovascular mortality}

Four studies $[9,15,21,22]$ reported the association between elevated lipoprotein(a) level and risk of all-cause mortality (Fig. 3). The pooled RR of all-cause mortality was 1.35 (95\% CI 0.93-1.95) for the highest vs. the lowest category of lipoprotein (a) level in a random effect model, with significant heterogeneity $\left(\mathrm{I}^{2}=73.9 \% ; p=\right.$
0.009). Four studies $[7,9,21,22]$ reported the association between elevated lipoprotein(a) level and risk of cardiovascular mortality (Fig. 4). The pooled RR of cardiovascular mortality was 1.43 (95\% CI $0.94-2.18$ ) for the highest vs. the lowest category of lipoprotein (a) level in a random effect model (Fig. 5), without significant heterogeneity $\left(\mathrm{I}^{2}=71.9 \% ; p=0.014\right)$. Sensitivity analyses by removing any study at each time slightly changed the original pooled effect sizes of all-cause and cardiovascular mortality (data not shown).

\section{Publication bias}

The funnel plot is potentially unreliable for less than the recommended arbitrary minimum number of 10 studies analyzed [26], so we did not construct the funnel plot to examine publication bias.

\section{Discussion}

The main findings of this meta-analysis is that an elevated lipoprotein (a) level is an independent predictor of cardiac and cardiovascular events in CAD patients. 


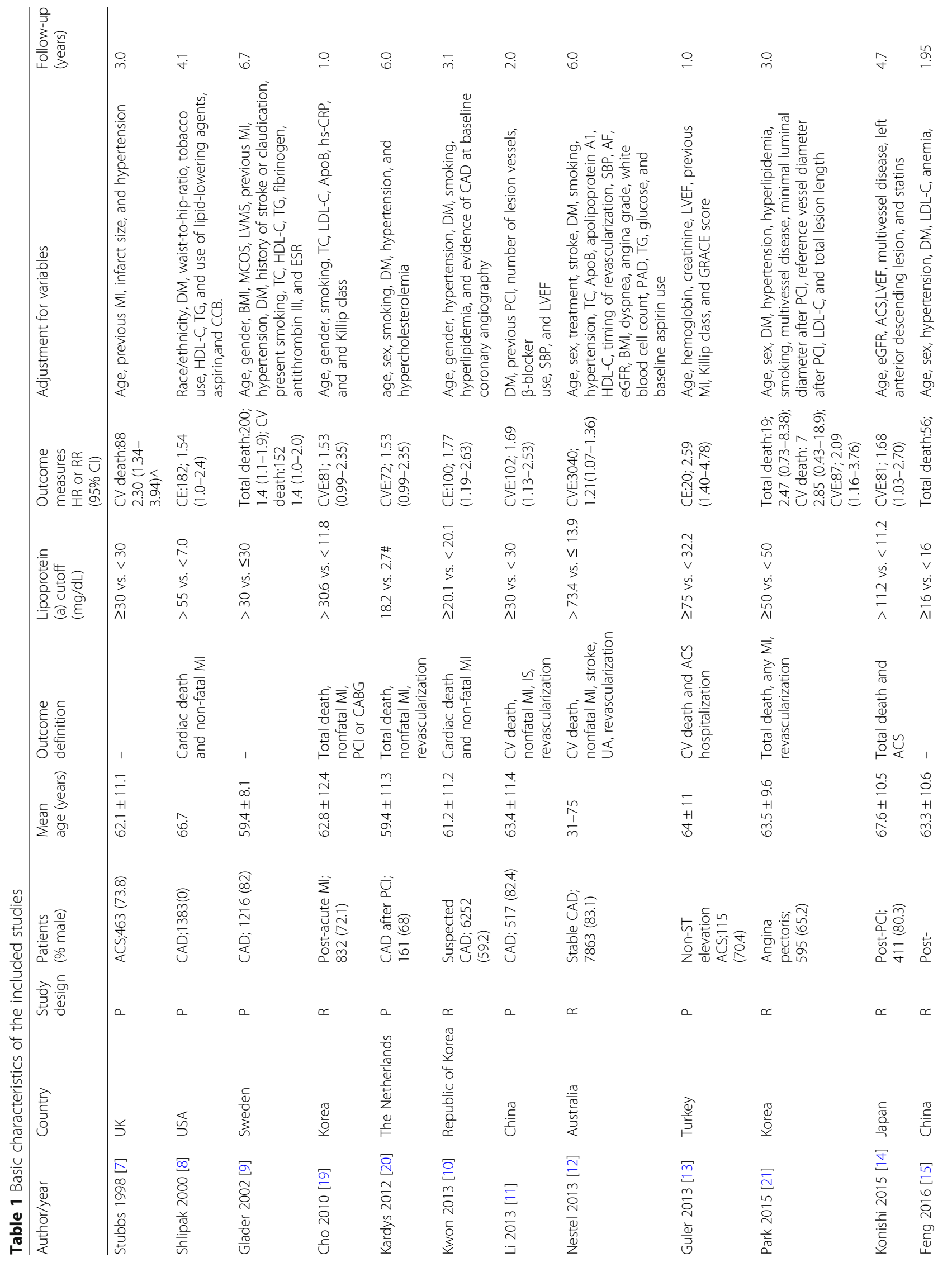




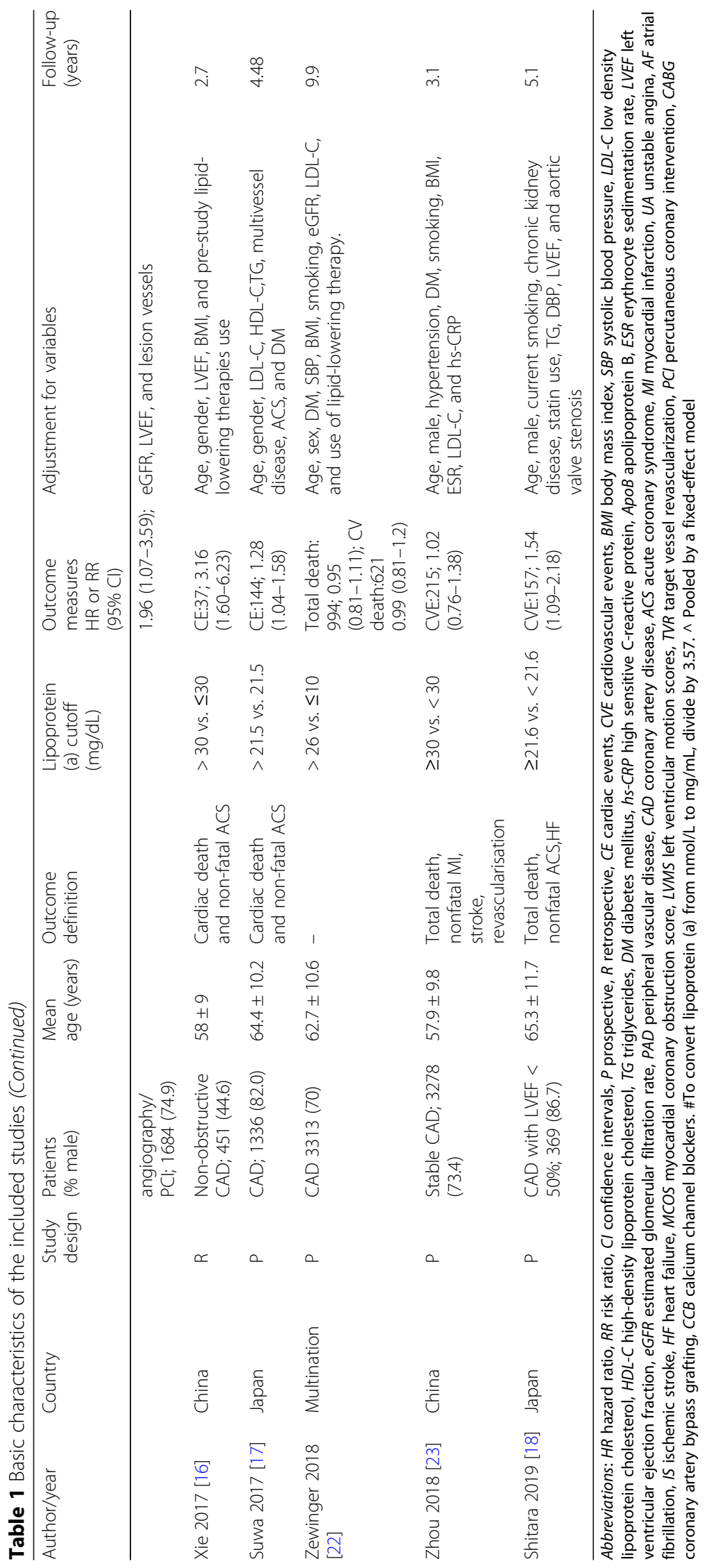




\begin{tabular}{|c|c|c|c|}
\hline Study & & & $\%$ \\
\hline ID & & $\mathrm{RR}(95 \% \mathrm{Cl})$ & Weight \\
\hline Shlipak (2000) & & $1.54(1.00,2.40)$ & 20.43 \\
\hline Kwon (2013) & & $1.77(1.19,2.63)$ & 22.07 \\
\hline Guler (2013) & & $2.59(1.40,4.78)$ & 14.60 \\
\hline Suwa (2017) & $\rightarrow$ & $1.28(1.04,1.58)$ & 30.00 \\
\hline Xie (2017) & & $3.16(1.60,6.23)$ & 12.91 \\
\hline Overall $($ I-squared $=61.9 \%, p=0.033)$ & & $1.78(1.31,2.42)$ & 100.00 \\
\hline NOTE: Weights are from random effects analysis & & & \\
\hline .161 & 1 & 23 & \\
\hline
\end{tabular}

Fig. 2 Forest plots showing pooled RR with $95 \% \mathrm{Cl}$ of cardiovascular events for the highest versus the lowest lipoprotein (a) level

These patients with the highest lipoprotein (a) level exhibited approximately 90 and $28 \%$ higher risk of cardiac and cardiovascular events, respectively, than those with the lowest lipoprotein (a) level. However, elevated baseline lipoprotein (a) level was not associated with an increased risk of cardiovascular and all-cause mortality in CAD patients.

The results presented our study are quite consistent with those of previous meta-analysis [27] showed that elevated lipoprotein (a) level was significantly associated with an increased risk of cardiovascular events in patients with established CAD. However, this well-designed metaanalysis did not evaluate the association of lipoprotein (a) with cardiovascular and all-cause mortality. Another individual patient-data meta-analysis [28] indicated that elevated baseline lipoprotein (a) exhibited an independent approximately linear association with cardiovascular events in patients with established cardiovascular disease.

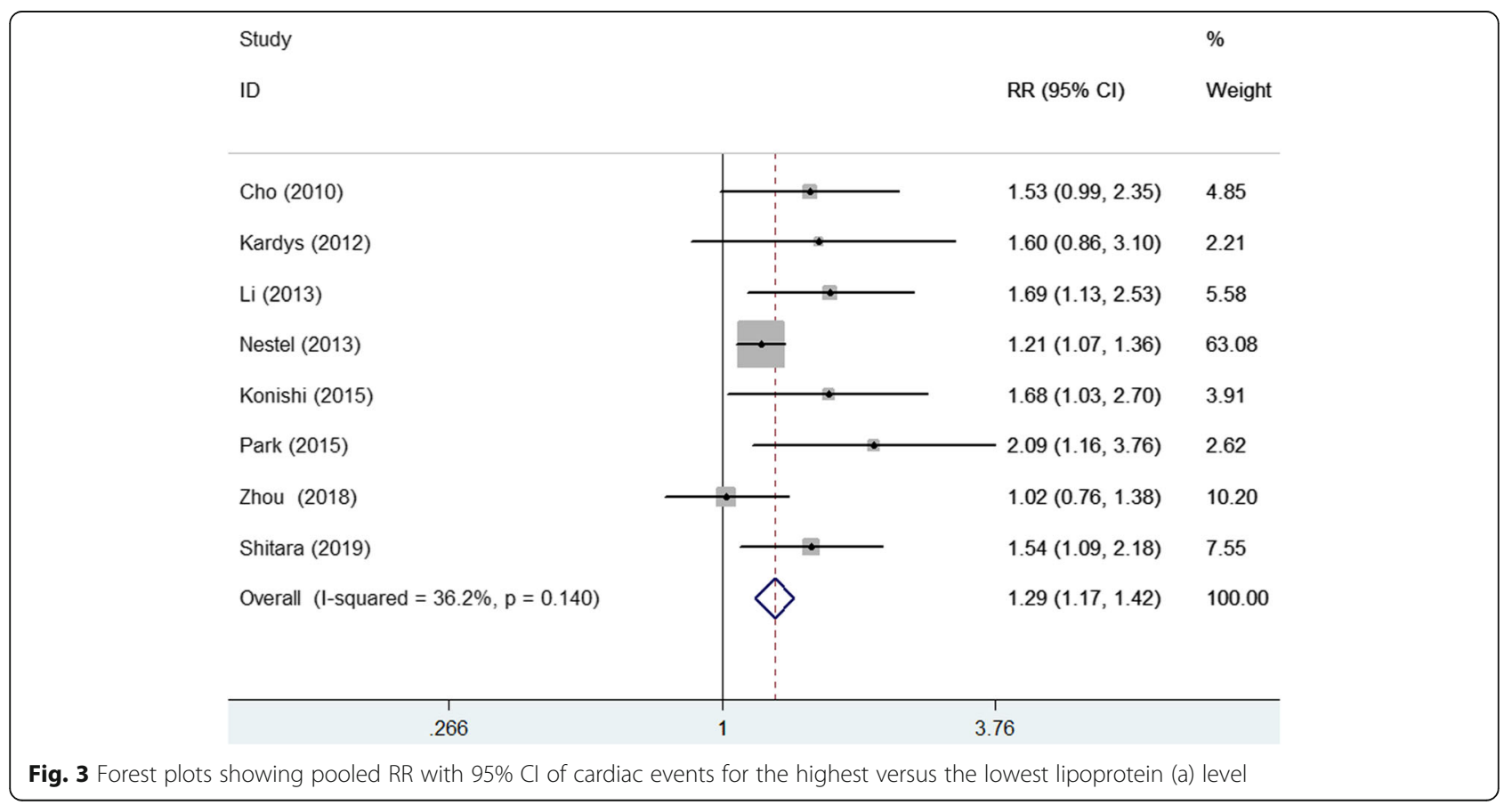




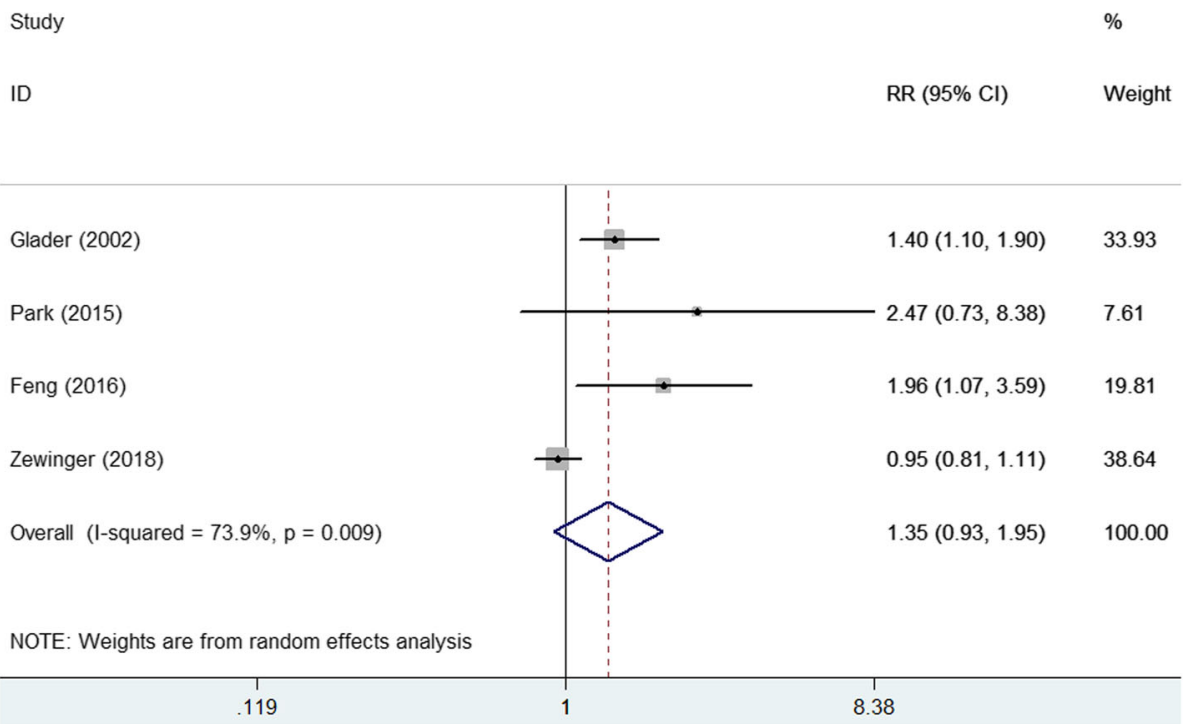

Fig. 4 Forest plots showing pooled RR with $95 \% \mathrm{Cl}$ of all-cause mortality for the highest versus the lowest lipoprotein (a) level

Consistent with previous meta-analyses, our study confirmed the prognostic role of lipoprotein (a) for predicting cardiovascular events in CAD patients. Additionally, analysis of lipoprotein (a) level by continuous variables further supported the prognostic significance of elevated lipoprotein (a) level for predicting cardiac and cardiovascular events in these patients [17, 29]. Elevated lipoprotein (a) level has been demonstrated to correlate with a higher mortality rate not only in subjects at high and intermediate risk, but also in young women with a low cardiovascular risk profile [30].
Our subgroup analysis further supported the prognostic value of lipoprotein (a) level for predicting cardiovascular events. There was a close association between elevated lipoprotein(a) level and higher risk cardiovascular events in the subgroup with follow-up duration $<2$ years in the current meta-analysis, suggesting that the prognostic value of lipoprotein (a) level weakened with the lengthening of the follow-up duration. Kardys' study [20] also showed that lipoprotein (a) was associated with a 3.1-fold increased 1-year risk of cardiovascular events but lost significance with long-term follow-up. CAD is a

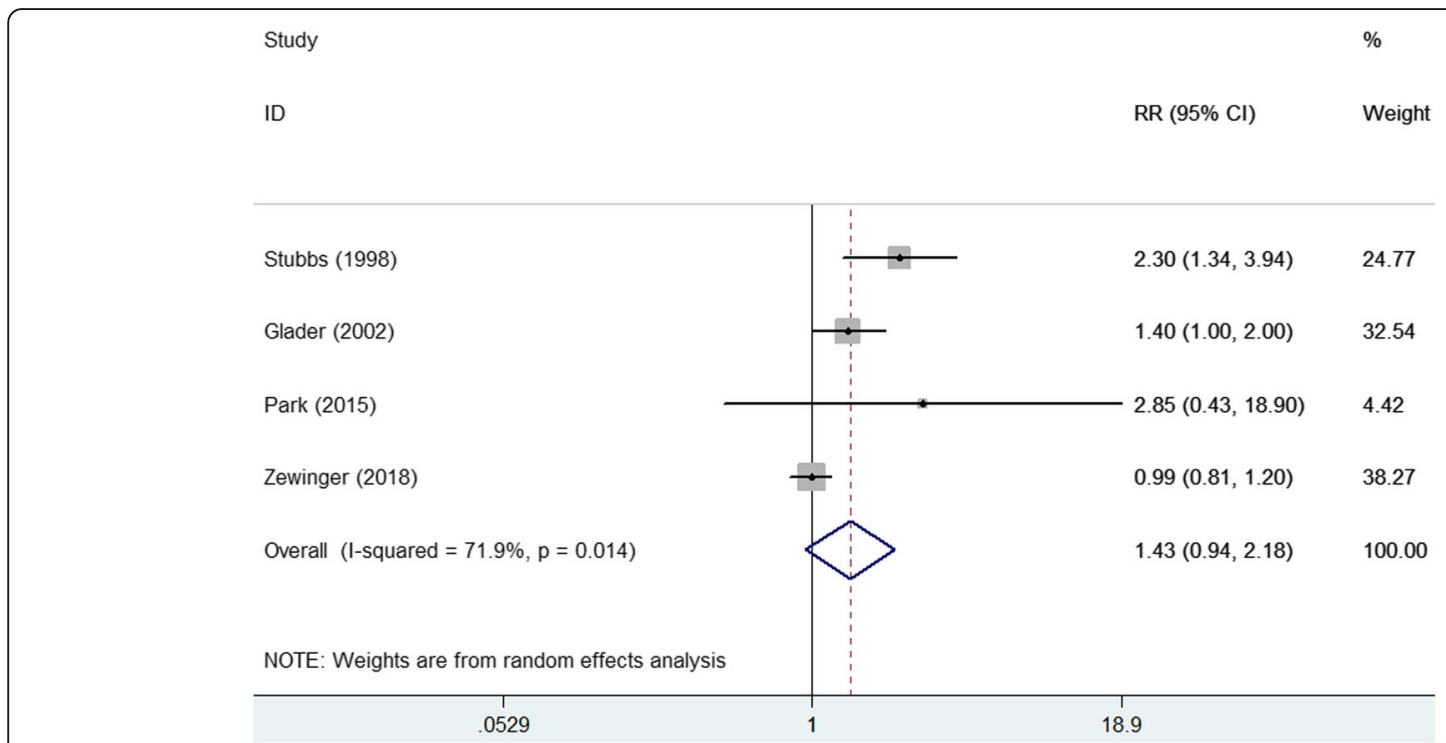

Fig. 5 Forest plots showing pooled RR with $95 \% \mathrm{Cl}$ of cardiovascular mortality for the highest versus the lowest lipoprotein (a) level 
heterogeneous condition, which spans from stable clinical condition to acute myocardial infarction. Notably, the effect of elevated lipoprotein (a) level on clinical outcomes was different between patients with and without ACS [18]. However, we could not perform subgroup analysis by subtype of CAD due to insufficient data.

Despite attaining the target low-lipid profile, a number of CAD patients remain at risk for cardiovascular events [31]. Elevated lipoprotein (a) level may account for some of the residual cardiovascular risk. Lipoprotein (a) could predict worse clinical outcomes even for patients with CAD who achieved target lipid level [14]. Importantly, determination of lipoprotein (a) level may also help to identify patients who require more intensive treatment. Future studies are warranted to evaluate whether lowering lipoprotein (a) level can offer cardiovascular benefits in patients with CAD.

Both life-style improvement and available lipidlowering drugs seem to poorly affect blood levels of lipoprotein (a) [32, 33]. Mild reduction achievable with PCKS9 inhibitors or niacin seems not to be related to reduce cardiovascular events [34]. Therefore, there are still unmet clinical demands in the management of dyslipidemia.

The mechanisms accounting for predictive value of lipoprotein (a) among CAD patients remain unclear. One potential explanation may be lipoprotein (a) mediating proinflammatory and antifibrinolytic effects [35]. Another explanation is that elevated lipoprotein (a) can damage endothelial and anticoagulant function by promoting endothelial dysfunction and increasing phospholipid oxidation [36, 37].

Several potential limitations of this meta-analysis should be acknowledged. First, this is not an individuallevel meta-analysis and patients' characteristics may have potential to affect the pooling results. Second, the cutoff value of elevated blood lipoprotein (a) level varied across studies and we could not define the appropriate cutoff value of lipoprotein (a) elevation. Third, moderate heterogeneity was observed in the pooling cardiac events and all-cause mortality. The heterogeneity may be partly explained by the subtype of CAD, study design, followup duration, methods for measuring lipoprotein (a), and cutoff value of lipoprotein(a) elevation. Fourth, due to insufficient data from the eligible studies, we failed to evaluate the prognostic role of lipoprotein (a) level by continuous data due to insufficient studies. Finally, we did not construct the funnel plot for detecting publication bias due to the analyzed studies was less than the recommended arbitrary minimum number of 10 .

\section{Conclusions}

The current meta-analysis indicates that elevated lipoprotein (a) level is an independent predictor of cardiac and cardiovascular events in CAD patients. As for lipoprotein(a) level is less affected by lifestyle, diet and medical therapy, measurement of lipoprotein (a) level has potential to improve the risk stratification CAD patients. Future well-designed studies are warranted to investigate whether the prognostic utility of lipoprotein(a) level is different subtype CAD patients.

\section{Additional files}

Additional file 1: Table S1. Quality assessment of the included studies (DOC $64 \mathrm{~kb}$ )

Additional file 2: Table S2. Subgroup analyses on cardiovascular events (DOC $41 \mathrm{~kb}$ )

\section{Abbreviations}

CAD: Coronary artery disease; Cl: Confidence interval; HR: Hazard ratio; NOS: Newcastle-Ottawa Scale; OR: Odds ratio; RR: Risk ratio

\section{Acknowledgements}

Not applicable.

\section{Authors' contributions}

ZM Wang and XC Zhai searched the literature, extracted data, and evaluated the study quality. M Xue and WJ Cheng performed the statistical analysis.

ZM Wang drafted the manuscript and XC Zhai revised the manuscript. HS

Hu designed the study and interpreted the results. All the authors approved the final version of manuscript to be published.

\section{Funding}

This work was supported by Science and Technology Development Planning of Shandong Province (2015GSF118022).

Availability of data and materials

All data generated or analyzed during this study are included in this article.

Ethics approval and consent to participate

Not applicable.

Consent for publication

Not applicable.

Competing interests

The authors declare that they have no competing interests.

\section{Author details}

${ }^{1}$ Department of Cardiology, Shandong Provincial Qianfoshan Hospital, the First Hospital Affiliated with Shandong First Medical University, NO. 16766, Jingshi Road, Jinan city, Jinan 250014, Shandong Province, China.

${ }^{2}$ Department of Geriatrics, Municipal Hospital of Zibo City, Zibo City 255000, Shandong Province, China.

Received: 21 May 2019 Accepted: 26 June 2019

Published online: 08 July 2019

References

1. Benjamin EJ, Blaha MJ, Chiuve SE, Cushman M, Das SR, Deo R, de Ferranti SD, Floyd J, Fornage M, Gillespie C, et al. Heart disease and stroke Statistics2017 update: a report from the American Heart Association. Circulation. 2017;135(10):e146-603.

2. Schiele F, Ecarnot F, Chopard R. Coronary artery disease: risk stratification and patient selection for more aggressive secondary prevention. Eur J Prev Cardiol. 2017;24(3_suppl):88-100.

3. Ramasamy I. Recent advances in physiological lipoprotein metabolism. Clin Chem Lab Med. 2014;52(12):1695-727.

4. Tsimikas S, Fazio S, Ferdinand KC, Ginsberg HN, Koschinsky ML, Marcovina SM, Moriarty PM, Rader DJ, Remaley AT, Reyes-Soffer G, et al. NHLBI working group 
recommendations to reduce lipoprotein(a)-mediated risk of cardiovascular disease and aortic stenosis. J Am Coll Cardiol. 2018;71(2):177-92

5. Kassner U, Schlabs T, Rosada A, Steinhagen-Thiessen E. Lipoprotein(a)--an independent causal risk factor for cardiovascular disease and current therapeutic options. Atheroscler Suppl. 2015;18:263-7.

6. Genser B, Dias KC, Siekmeier R, Stojakovic T, Grammer T, Maerz W. Lipoprotein (a) and risk of cardiovascular disease--a systematic review and meta analysis of prospective studies. Clin Lab. 2011;57(3-4):143-56.

7. Stubbs P, Seed M, Lane D, Collinson P, Kendall F, Noble M. Lipoprotein(a) as a risk predictor for cardiac mortality in patients with acute coronary syndromes. Eur Heart J. 1998;19(9):1355-64.

8. Shlipak MG, Simon JA, Vittinghoff E, Lin F, Barrett-Connor E, Knopp RH, Levy Rl, Hulley SB. Estrogen and progestin, lipoprotein(a), and the risk of recurrent coronary heart disease events after menopause. JAMA. 2000; 283(14):1845-52.

9. Glader CA, Birgander LS, Stenlund H, Dahlen GH. Is lipoprotein(a) a predictor for survival in patients with established coronary artery disease? Results from a prospective patient cohort study in northern Sweden. J Intern Med. 2002;252(1):27-35.

10. Kwon SW, Lee BK, Hong BK, Kim JY, Choi EY, Sung JM, Rhee JH, Park YM, Ma DW, Chung H, et al. Prognostic significance of elevated lipoprotein(a) in coronary artery revascularization patients. Int J Cardiol. 2013;167(5):1990-4.

11. Li ZG, Li G, Zhou YL, Chen ZJ, Yang JQ, Zhang Y, Sun S, Zhong SL. Lack of association between lipoprotein(a) genetic variants and subsequent cardiovascular events in Chinese Han patients with coronary artery disease after percutaneous coronary intervention. Lipids Health Dis. 2013;12:127.

12. Nestel PJ, Barnes EH, Tonkin AM, Simes J, Fournier M, White HD, Colquhoun DM, Blankenberg S, Sullivan DR. Plasma lipoprotein(a) concentration predicts future coronary and cardiovascular events in patients with stable coronary heart disease. Arterioscler Thromb Vasc Biol. 2013;33(12):2902-8.

13. Guler E, Gecmen C, Guler GB, Karaca O, Agus HZ, Gunes HM, Batgerel U, Elveran A, Esen AM. Adding lipoprotein(a) levels to the GRACE score to predict prognosis in patients with non-ST elevation acute coronary syndrome. Kardiol Pol. 2013;71(7):695-701.

14. Konishi H, Miyauchi K, Kasai T, Tsuboi S, Ogita M, Naito R, Sai E, Fukushima Y, Katoh Y, Okai I, et al. Impact of lipoprotein(a) as residual risk on long-term outcomes in patients after percutaneous coronary intervention. Am J Cardiol. 2015;115(2):157-60

15. Feng Z, Li HL, Bei WJ, Guo XS, Wang K, Yi SX, Luo DM, Li XD, Chen SQ, Ran $P$, et al. Association of lipoprotein(a) with long-term mortality following coronary angiography or percutaneous coronary intervention. Clin Cardiol. 2017:40(9):674-8.

16. Xie H, Chen L, Liu H, Cui Y, Zhang Z, Cui L. Long-term prognostic value of lipoprotein(a) in symptomatic patients with nonobstructive coronary artery disease. Am J Cardiol. 2017;119(7):945-50.

17. Suwa S, Ogita M, Miyauchi K, Sonoda T, Konishi H, Tsuboi S, Wada H, Naito R, Dohi T, Kasai T, et al. Impact of lipoprotein (a) on Long-term outcomes in patients with coronary artery disease treated with statin after a first percutaneous coronary intervention. J Atheroscler Thromb. 2017:24(11):1125-31.

18. Shitara J, Kasai T, Konishi H, Endo H, Wada H, Doi S, Naito R, Tsuboi S, Ogita M, Dohi T, et al. Impact of lipoprotein (a) levels on Long-term outcomes in patients with coronary artery disease and left ventricular systolic dysfunction. Circ J. 2019;83(5):1047-53.

19. Cho JY, Jeong MH, Ahn Y, Hong YJ, Park HW, Yoon NS, Yoon HJ, Kim KH, Kim JH, Cho JG, et al. High lipoprotein(a) levels are associated with Longterm adverse outcomes in acute myocardial infarction patients in high Killip classes. Korean Cir J. 2010:40(10):491-8.

20. Kardys I, Oemrawsingh RM, Kay IP, Jones GT, McCormick SP, Daemen J, Van Geuns RJ, Boersma E, Van Domburg RT, Serruys PW. Lipoprotein(a), interleukin-10, C-reactive protein, and 8-year outcome after percutaneous coronary intervention. Clin Cardiol. 2012;35(8):482-9.

21. Park SH, Rha SW, Choi BG, Park JY, Jeon U, Seo HS, Kim EJ, Na JO, Choi CU, Kim JW, et al. Impact of high lipoprotein(a) levels on in-stent restenosis and long-term clinical outcomes of angina pectoris patients undergoing percutaneous coronary intervention with drug-eluting stents in Asian population. Clin Exp Pharmacol Physiol. 2015;42(6):588-95.

22. Zewinger S, Kleber ME, Tragante V, McCubrey RO, Schmidt AF, Direk K, Laufs U, Werner C, Koenig W, Rothenbacher D, et al. Relations between lipoprotein(a) concentrations, LPA genetic variants, and the risk of mortality in patients with established coronary heart disease: a molecular and genetic association study. Lancet Diabetes Endocrinol. 2017:5(7):534-43.
23. Zhou BY, Sun D, Wang C, Wu NQ, Guo YL, Zhu CG, Gao Y, Liu G, Dong Q, Li JJ: Plasma lipoprotein(a) concentration is associated with the coronary severity but not with events in stable coronary artery disease patients: a Chinese cohort study. Heart Lung Circ:https://doi.org/10.1016/j.hlc.2018. 1005.1190 .

24. Moher D, Liberati A, Tetzlaff J, Altman DG. Preferred reporting items for systematic reviews and meta-analyses: the PRISMA statement. Ann Intern Med. 2009;151(4):264-9 W264.

25. Wells G, Shea B, O'Connell D, Peterson J, Welch V, Losos M, Tugwell P: The Newcastle-Ottawa Scale (NOS) for assessing the quality if nonrandomized studies in meta-analyses. http://www.ohri.ca/programs/clinical_ epidemiology/oxford.asp. Assessed June 202019

26. Lau J, loannidis JP, Terrin N, Schmid CH, Olkin I. The case of the misleading funnel plot. Bmj. 2006;333(7568):597-600.

27. O'Donoghue ML, Morrow DA, Tsimikas S, Sloan S, Ren AF, Hoffman EB, Desai NR, Solomon SD, Domanski M, Arai K, et al. Lipoprotein(a) for risk assessment in patients with established coronary artery disease. J Am Coll Cardiol. 2014;63(6):520-7

28. Willeit P, Ridker PM, Nestel PJ, Simes J, Tonkin AM, Pedersen TR, Schwartz GG, Olsson AG, Colhoun HM, Kronenberg F, et al. Baseline and on-statin treatment lipoprotein(a) levels for prediction of cardiovascular events: individual patient-data meta-analysis of statin outcome trials. Lancet. 2018; 392(10155):1311-20

29. Dai W, Long J, Cheng Y, Chen Y, Zhao S. Elevated plasma lipoprotein(a) levels were associated with increased risk of cardiovascular events in Chinese patients with stable coronary artery disease. Sci Rep. 2018;8(1):7726.

30. Fogacci F, Cicero AF, D'Addato S, D'Agostini L, Rosticci M, Giovannini M, Bertagnin E, Borghi C, Brisighella Heart Study G. Serum lipoprotein(a) level as long-term predictor of cardiovascular mortality in a large sample of subjects in primary cardiovascular prevention: data from the Brisighella Heart Study. Eur J Intern Med. 2017;37:49-55.

31. Nicholls SJ, Tang WH, Scoffone H, Brennan DM, Hartiala J, Allayee H, Hazen SL. Lipoprotein(a) levels and long-term cardiovascular risk in the contemporary era of statin therapy. J Lipid Res. 2010;51(10):3055-61.

32. Fogacci F, Cicero AFG, D'Addato S, Giovannini M, Borghi C, Brisighella Heart Study G. Effect of spontaneous changes in dietary components and lipoprotein(a) levels: data from the Brisighella Heart Study. Atherosclerosis. 2017;262:202-4

33. Stein EA, Raal F. Future directions to establish lipoprotein(a) as a treatment for atherosclerotic cardiovascular disease. Cardiovasc Drugs Ther. 2016;30(1):101-8.

34. Boffa MB. Emerging therapeutic options for lowering of lipoprotein(a): implications for prevention of cardiovascular disease. Curr Atheroscler Rep. 2016:18(12):69.

35. Miles LA, Fless GM, Levin EG, Scanu AM, Plow EF. A potential basis for the thrombotic risks associated with lipoprotein(a). Nature. 1989;339(6222):301-3.

36. Schachinger V, Halle M, Minners J, Berg A, Zeiher AM. Lipoprotein(a) selectively impairs receptor-mediated endothelial vasodilator function of the human coronary circulation. J Am Coll Cardiol. 1997:30(4):927-34.

37. Leibundgut G, Arai K, Orsoni A, Yin H, Scipione C, Miller ER, Koschinsky ML, Chapman MJ, Witztum JL, Tsimikas S. Oxidized phospholipids are present on plasminogen, affect fibrinolysis, and increase following acute myocardial infarction. J Am Coll Cardiol. 2012;59(16):1426-37.

\section{Publisher's Note}

Springer Nature remains neutral with regard to jurisdictional claims in published maps and institutional affiliations.

Ready to submit your research? Choose BMC and benefit from:

- fast, convenient online submission

- thorough peer review by experienced researchers in your field

- rapid publication on acceptance

- support for research data, including large and complex data types

- gold Open Access which fosters wider collaboration and increased citations

- maximum visibility for your research: over $100 \mathrm{M}$ website views per year

At $\mathrm{BMC}$, research is always in progress.

Learn more biomedcentral.com/submissions 